\title{
Simbologia e Alegoria na Linguagem Alquímica
}

\section{À Helena Castro Silva}

No seu Vocabulário Português e Latino (1716), Raphael Bluteau refere-se à alquimia como sendo "Arte occulta, esta he particularmente a de converter qualquer metal em ouro; que se hâ tal arte no mundo, he na realidade taô oculta, que ou todos a ignorão, ou nenhum dos que a sabem, a manifesta". Deste modo, o autor ridiculariza e denuncia o secretismo comum à prática da alquimia recusando-se, no entanto, a negar completamente a possibilidade da existência da pedra filosofal. Bluteau atesta, deste modo, alguns dos problemas da alquimia mas também sugere um continuado e genuíno interesse na mesma em Portugal no século XVIII. A obra Ennaea ou Aplicação do Entendimento sobre a Pedra Filosofal, publicada em 1732 (1. ${ }^{\circ}$ vol.) e 1733 ( $2 .^{\circ}$ vol.), é particularmente ilustrativa desta continuada presença. É da autoria do médico do Reino Anselmo Caetano Munhos de Avreu e assume-se como "o primeiro Tratado português de alquimia explicitamente apresentado como tal". Na mesma, o autor insiste sobre o carácter espiritual da alquimia.

Tal como é sugerido em Ennaea, a alquimia deve ser entendida como tendo uma natureza dupla (ver figura 1). $\mathrm{Na}$ realidade, ao longo do seu percurso milenar, a alquimia englobou dois aspectos distintos mas complementares ${ }^{1}$. Uma das suas vertentes centralizou-se na sua componente prática e permite encarar a alquimia como uma arte ou ofício no qual são estudadas as relações e afinidades das coisas através de testes empíricos. Neste âmbito, a alquimia protagonizou o aparecimento dos primeiros laboratórios, estando na base do desenvolvimento de aparelhos, procedimentos e conhecimentos práticos essenciais à formação da ciência moderna ( ver figuras 2 e 3$)^{2}$. Por outro lado, a alquimia pode ser percepcionada como uma visão mística do mundo ${ }^{3}$. Neste contexto, a tarefa do verdadeiro alquimista era a de assistir a natureza no seu processo de aperfeiçoamento tendo como base não só a sua experiência laboratorial mas também a sua dedicação e inspiração divina. A sua matéria prima não seria tanto a que reagia nos fornos e alambiques, mas o indivíduo que reage sobre ele próprio. Para o verda- deiro alquimista, mais importante do que propriamente alcançar a transformação dos metais era atingir o seu aperfeiçoamento pessoal, a transformação da sua alma ${ }^{4}$. Um exemplo de uma comparação explicita entre a Doutrina Cristã e a teoria alquímica encontra-se na seguinte passagem atribuída a Nicolas Flamel:

Behold...our Saviour... who shall eternally unity unto him all pure and clean souls, and will drive away all impurity and uncleaness, as being unworthy to his divine Body. So by comparison (but first asking leave of the Catholic, Apostolic and Roman Church, to speak in this manner...) see here our white Elixir,

figura 1 Laboratório Alquimico, David Teniers, século XVII. Teniers foi um dos artistas que tratou com mais frequência o tema da alquimia.

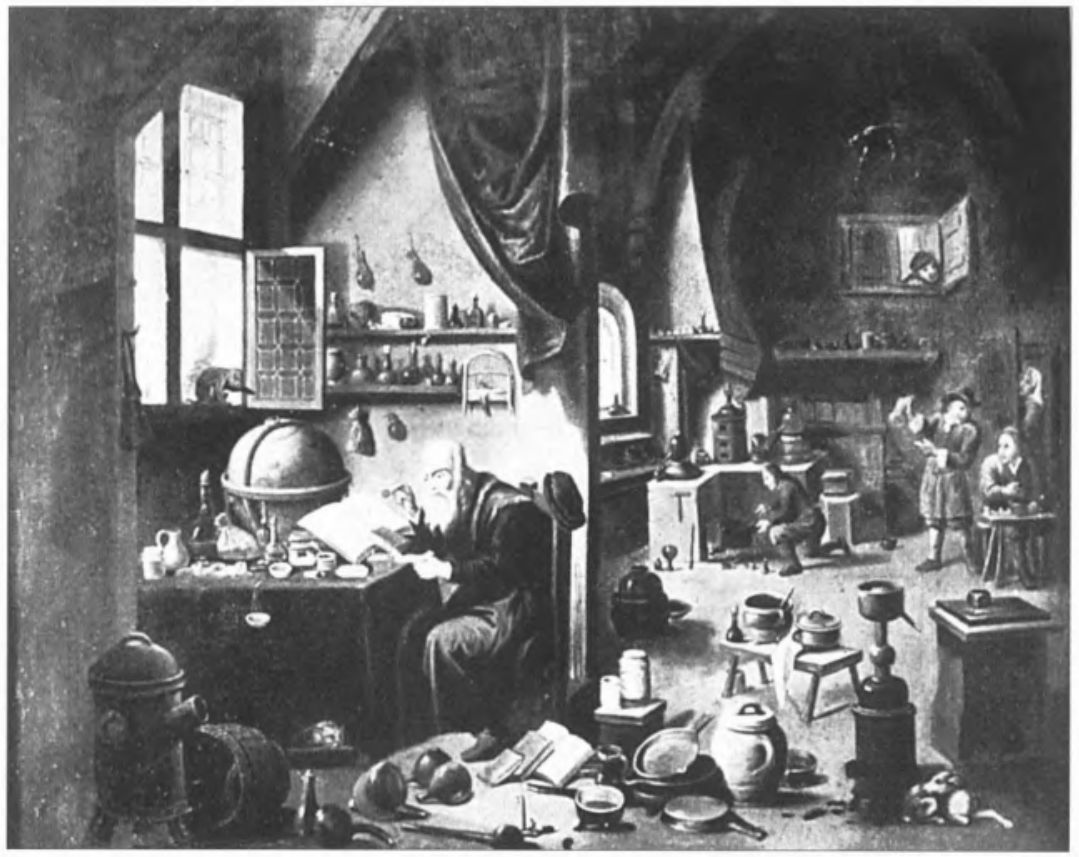

* Faculdade de Ciências e Tecnologia, Universidade Nova de Lisboa. 


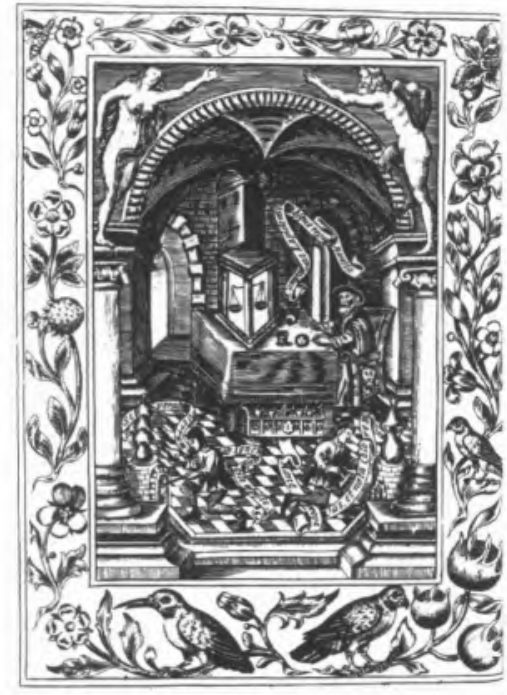

figura 2 Laboratório alquímico com uma balança. In Theatrum Chemicum Britannicum, ed. Elias Ashmole, 1652.

which from henceforward will inseparably unite unto itself every pure Metalic nature, changing it into its own most fine silvery nature, rejecting all that is impure, strange, Heterogeneal, or of another kind ${ }^{5}$.

0 hermeticismo habitualmente associado à alquimia foi especialmente veiculado através da sua linguagem simbólica e figurativa. Uma das razōes subjacentes ao secretismo típico da linguagem alquímica está relacionada com uma concepção fechada do conhecimento na qual este não pode ser revelado a todos por ser entendido como um domínio sagrado e retentor de poder. Para além disso, a simbologia da linguagem alquímica está intimamente ligada a uma concepção holística do universo, na qual tudo estava interligado e a natureza devia ser entendida como uma entidade activa, orgânica e animista. Nesta concepção, o conhecimento seria obtido através dos sentidos e do estudo das relações espirituais e simbólicas subjacentes à unidade do mundo e que unem os seus vários componentes?.

Uma relação bastante importante para os alquimistas era a analogia microcosmos/macrocosmos ${ }^{8}$. Ela consubstanciava um entendimento holístico do lugar do Homem e no Universo ao pressupor que todos os aspectos do microcosmos (humanidade) estavam de algum modo reflectidos no macrocosmos (universo) e sujeitos à sua influência (ver figura 4). A relevância desta analogia permite entender a frequente correlação entre as doenças humanas e a imperfeição dos metais (por exemplo, a designação da prata como ouro leproso); a classificação das substâncias em corpos (substâncias sólidas) e espiritos (substâncias voláteis); a correlação entre as fases da vida humana e as fases do trabalho alquímico (por exemplo, a preparação da pedra filosofal era usualmente descrita como tendo a duração de nove meses); a utilização de uma simbologia sexual na classificação dos corpos (por exemplo, o ouro, enxofre, fogo e ar como masculinos e a prata, mercúrio, água e terra como femininos). De utilizaçăo frequente eram também as associações da conversão do chumbo em ouro à alteração do carácter humano de baixeza para nobreza; a imutabilidade do ouro à vida eterna que aguardaria os eleitos de Deus; e o homem mais nobre (rei) ao metal mais nobre (ouro).

A simbologia da linguagem alquímica encontra-se também patente na designação de metais pelos nomes e símbolos dos planetas: ouro/Sol, prata/Lua, ferro/Marte, mercúrio, estanho/Júpiter, chumbo/Saturno, cobre/Vénus (ver figura 5). De modo análogo, a associção das várias operações laboratoriais aos signos do zodiaco é ilustrativa da linguagem alegórica própria da alquimia e da importância de analogias baseadas na astrologia: calcinação/carneiro, congelação/touro, fixacão/gémeos, dissolução/caranguejo, digestão/leão, destilação/virgem, sublimação/balança, separação/escorpião, ceração/sagitário, fermentação/capricórnio. A utilização frequente de alegorias baseadas na astronomia e na astrologia fazia com que, por vezes, fosse difícil identificar como pertencendo à alquimia determinados textos. Um exemplo significativo é o seguinte excerto da obra alquimica Turba Philosophorum (1613):

I signify that the envious have narrated and said that the splendour of Saturn does not appear unless it perchance the dark when it ascends in the air, that

figura 3 "O oratório e o laboratório", Heinrich Khunrath, 1609. O nome de Deus aparece em caracteres hebraicos em cima do oratório; a inscrição latina significa "quando nos devotamos apenas ao nosso trabalho, Deus ajuda-nos". A mesa central contém instrumentos musicais simbólicos da importância da música e da harmonia nas tarefas alquimicas

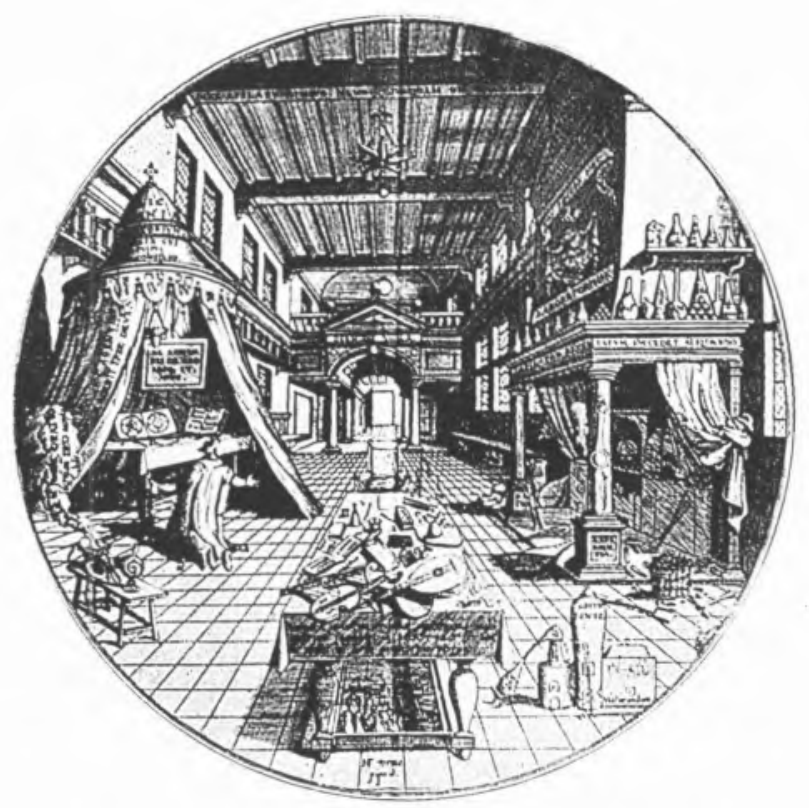




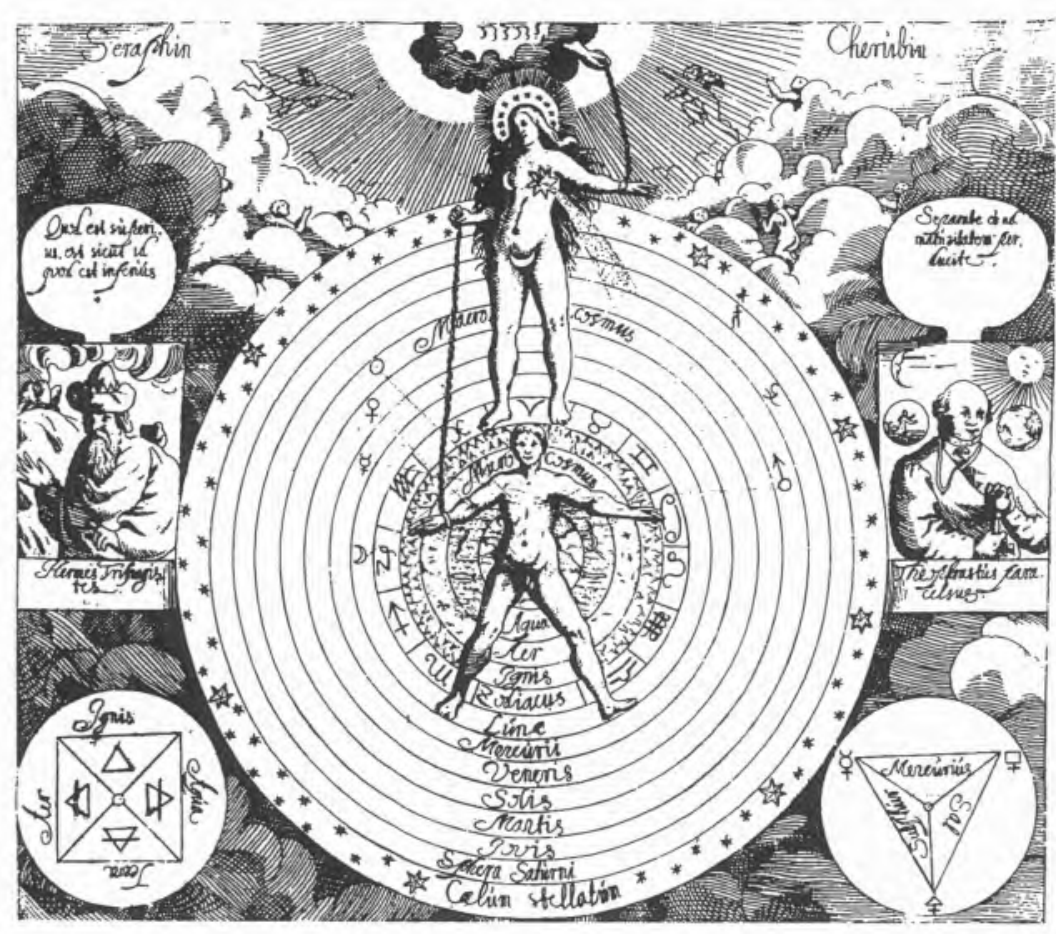

Mercury is hidden by the rays of the sun, that quicksilver (argentum vivum) vivifies the body by its fiery strength, and thus the work is accomplished. But Venus when she becomes oriental, precedes the sun. 9

Analogias baseadas no reino animal eram também utilizadas com alguma frequência na linguagem alquímica. Para além da mítica e tradicional serpente que morde a própria causa, símbolo ao mesmo tempo da unidade cósmica e da longevidade e eternidade da matéria (ver figura 6), outros dos animais representados incluiam o leão verde para designar o cobre, a águia para referenciar o sal amoniacal, e os peixes para aludir ao mercúrio. Determinados pássaros eram por vezes utilizados para indicar uma alteração de cor num processo alquímico (em especial, o pavão, o corvo e o cisne) ou a volatilidade (normalmente simbolizada pela águia). Os pássaros podiam ser usados nāo só para designar substâncias ou cores mas também para indicar operações laboratoriais tais como o processo de destilação. Este processo era muitas vezes considerado como sendo composto por uma evaporação e uma condensação representadas, respectivamente, por um pássaro a subir e outro a descer. Sendo assim, o processo completo da destilação era, com alguma fre- quência, representado por dois pássaros voando em sentido contrário. 10

A riqueza simbólica da linguagem alquímica incluia também representaçôes pictóricas tais como as apresentadas nas figuras 7 e 8 . A primeira destas figuras pretende descrever as quatro operações dos processos alquímicos, Solutio, Ablutio, Conjunctio e Fixio, representadas respectivamente da esquerda para direita no interior dos balões posicionados na cabeça das quatro mulheres. Esta figura representa também os quatro elementos Terra, Água, Ar e Fogo, respectivamente da esquerda para a direita nas esferas que se encontram na parte inferior da figura. No que respeita à figura 8 , trata-se da primeira ilustração da obra As Dose Chaves da Filosofia (1609) do célebre alquimista Basilio Valentim. ${ }^{11}$ Esta ilustração simboliza o processo de purificação do ouro e da prata representados, respectivamente, pelo Rei e pela Rainha. No lado esquerdo, o lobo significa o antimónio que era normalmente utilizado na purificação do ouro. No lado direito encontrase representada a purificação da prata pelo chumbo. Este metal é identificado pelo homem idoso com uma gadanha. No enigmático texto que acompanha a gravura pode ler-se: figura 40 Homem como o microcosmos ligado ao seu criador pela cadeia da natureza representada por uma mulher. É de notar os retratos de Hermes Trimegisto e de Paracelso, respectivamente à esquerda e à direita da figura, bem como o diagrama dos quatro elementos e dos três principios paracelsianos. In Tobias Scutz, Harmonia macrocosmi cum microcosmi, 1654).

Que a coroa do Rei seja de ouro muito puro, e que o juntem com a sua casta esposa. Assim pois, se queres operar nas nossas matérias pega um lobo esfomeado e resplandecente ligado por causa da etimologia do seu nome ao guerreiro Marte, mas tendente à de Saturno por ser seu filho.

Encontra-se nos vales e nas montanhas, sempre agonizante. Deita-lhe o corpo de Rei para que se sacie, e depois de o ter comido, deita-os num grande fogo para que sejam completamente consumidos e o Rei será libertado. Depois de teres feito isto três vezes, o Leão terá ultrapassado completamente o Lobo e o Lobo já não poderá exterminar o Rei, e a nossa matéria estará preparada e pronta para começar a obra.

Na linguagem simbólica e multifacetada da alquimia, a natureza era apresentada como uma rede de relaçōes. À riqueza desta linguagem correspondiam, no entanto, graves dificuldades em termos de acessibilidade e comunicação. Um dos problemas mais imediatos consistia nas dificuldades em identificar a complexa simbologia verbal e pictórica associada à linguagem alquímica. A interpretação desta linguagem exigia não só o exercicio renovado da leitura mas também um verdadeiro processo de iniciação. É precisamente nesta base que é fundamen- 
figura 5 Tabela de simbolos químicos. In N. Lémery, Cours de Chimie (1675)

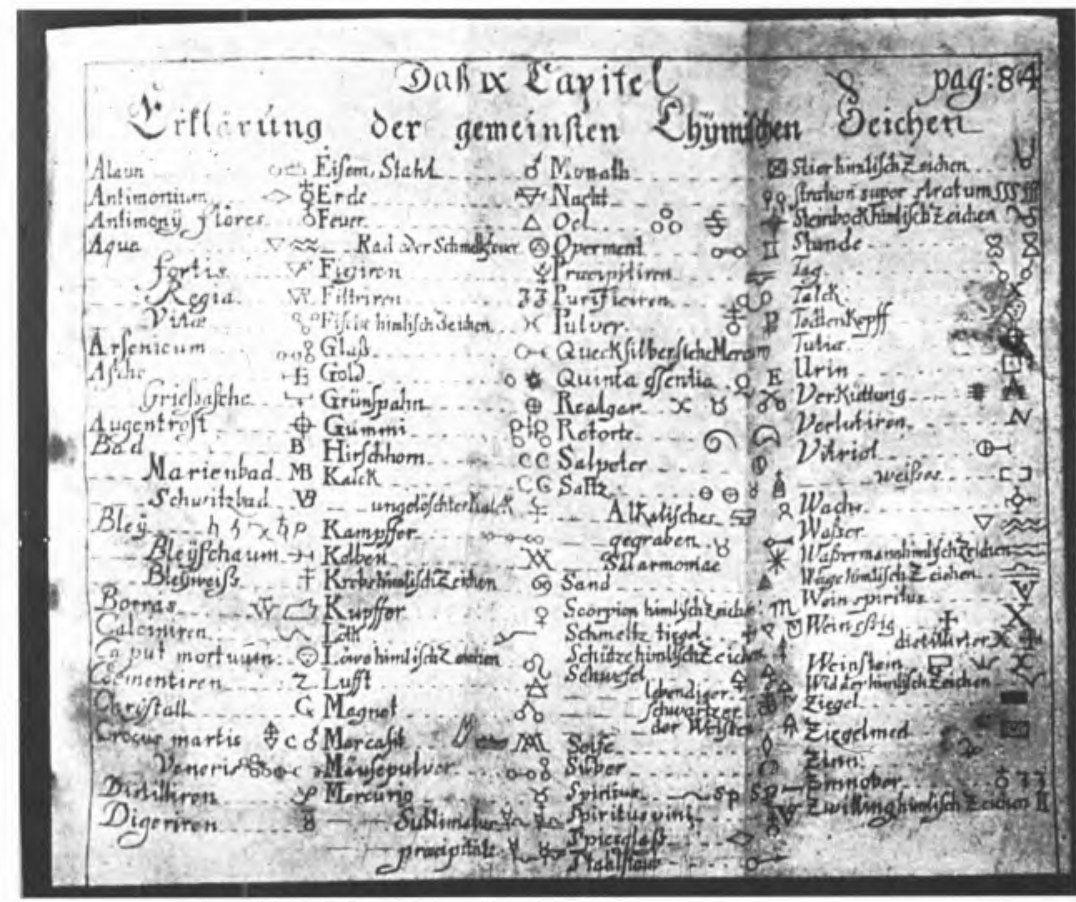

ainda, no facto de o mesmo nome poder corresponder a substâncias diferentes (por exemplo, a substância actualmente designada por Sulfato de Potássio podia ser nomeada por nove nomes diferentes incluindo panacea duplicata, panacea holsatica, arcanum duplicatum, sal duplicatum, arcanum holsteinense, tartarum vitriolum, nitrium vitriolum, sal polychrestum glaser, vitriolum potassium). No século XVI, um autor chegou mesmo a dar cerca de cem nomes ao mercúrio, incluindo designações como "água viva", "águia voadora", "cauda do dragão", "fumo branco" e "segredo total", 14 Para além disso, outra dificuldade consistia no facto de o nome, muitas vezes não traduzir a composição das substâncias mas, em vez disso, traduzir não só analogias alquímicas, como também analogias culinárias (por exemplo, óleo de vitriol, manteiga de antimónio, fígado de enxofre, creme de tártaro, açúcar de Saturno), ou o local onde as substâncias podiam ser encontradas (por exemplo, o nome cobre provém da palavra Cubrum porque este metal se encontrava principalmente na ilha de Chipre (Cuprius)). Alguns destes problema foram explicitamente abordados por Robert Boyle na sua obra The Sceptical Chymist (1661):

I find that even Eminent Writers do so abuse the terms they employ, that as they will now and the give diverse things, one name; so they will oftentimes give one thing, many names; and some of them (perhaps) such as do much more properly signifie some distinct Body of another kind; may even in the Technical Words or Terms of Art, they refrain not from this Confounding Liberty; but will, as I have Observed, call the same Substance, sometimes the Sulphur, and sometimes the Mercury of a Body. 15

Também Christopher Glaser no seu Tratado de Química (1668) ataca a prática comum de autores anteriores "terem escrito de um modo tão obscuro e terem retirado prazer ao confundir as mentes e ao conduzi-las para labirintos". Ao distanciar-se de publicações anteriores, as declarações de Glaser funcionavam também como uma estratégia de autopromoção da sua obra e carreira no ensino da química.

A ausência de um sistema para a designação das substâncias químicas começou a ser especialmente crítica na segunda metade do século XVIII, quando novos elementos foram descobertos e novos compostos foram preparados pela primeira vez. Em 1780, tinha-se já procedido à identificação de 17 novos metais. Por outro lado, as experiências de Joseph Black, Henry Cavendish e Joseph Priestley (1733-1804) iniciavam o 


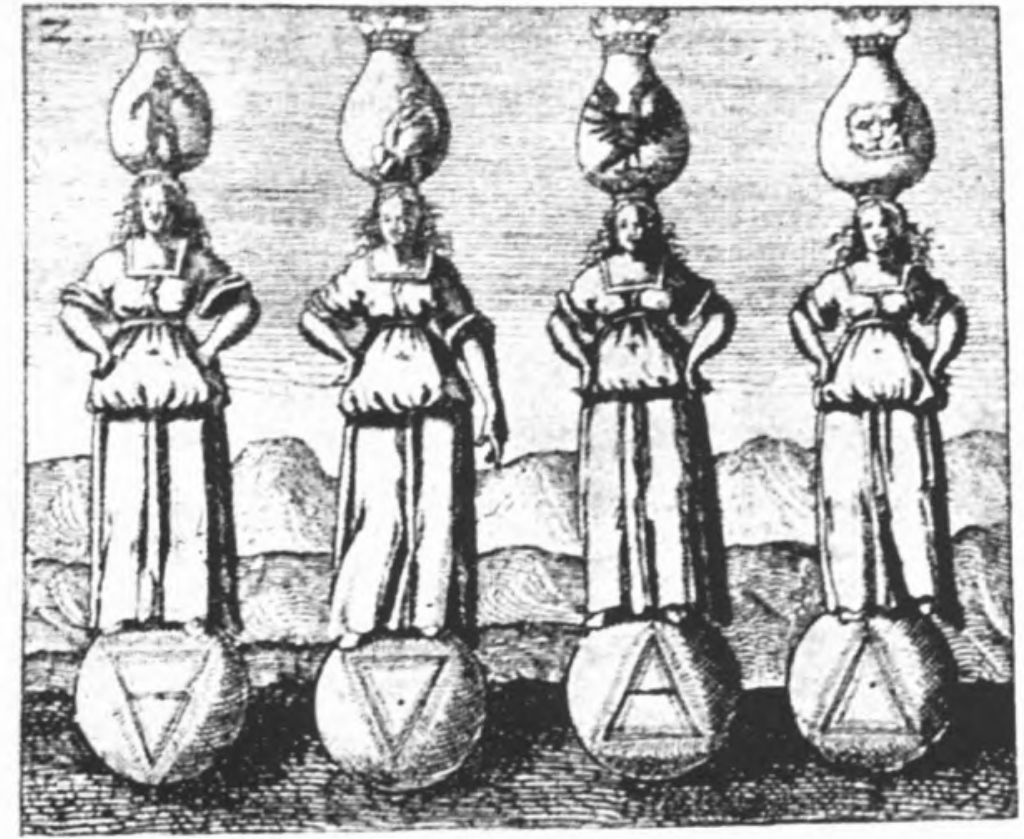

novo ramo da Química pneumática, fazendo com que os compostos gasosos aumentassem a lista dos compostos conhecidos: "o ar tirado do espírito do sal", "o ar tirado do óleo de vitriol", "o ar alcalino", "o ar flogisticado", "o ar desflogisticado", "o ar inflamável". 16 Para evitar a ambiguidade de alguns dos termos corrrentes, alguns autores começaram a utilizar longas frases descritivas quando falavam dos compostos. Na década de 1780, Antoine Laurent Lavoisier estabelece definitivamente a composição do ar atmosférico e a composição da água (pondo em causa a teoria dos quatro elementos) e argumenta para a necessidade de se fixar um nome para cada uma das novas subtâncias. Até à reforma da nomenclatura, Lavoisier acaba por utilizar vários nomes para designar o oxigénio: "parte salubra do ar", "ar puro", "ar vital", "ar eminentemente respirável" e "princípio oxigínio".

Torbern Olof Bergman foi um dos primeiros químicos a defender a necessidade de uma sistematização da linguagem química. A reforma da nomenclatura na Botânica empreendida por Lineu, seu compatriota, parece ter influenciado a atitude de Bergman relativamente à linguagem química. Lineu tinha classificado as plantas de acordo com os seus elementos constituintes, abstraindo-se de considerações basea- das na cor, nas propriedades medicinais ou no país de origem. Utilizou o latim uma nomenclatura binomial, com o nome do género a proceder o da espécie. Apenas em alguns casos deixou persistir nomes triviais que exprimiam uma propriedade das plantas ou cujo uso se tinha generalizado. 0 sistema foi aceite ainda durante a sua vida e trouxe grandes vantagens à Botânica. Muitas das alterações da nova nomenclatura química teriam como modelo as alterações de Lineu na classificação botânica. ${ }^{17}$

Seria, no entanto, a associação de Guyton de Morveau a Lavoisier, ClaudeLouis Berthollet e Antoine François de Fourcroy que permitiria levar a cabo a reforma da nomenclatura química em 1787. O novo Méthode de Nomenclature Chimique então publicado apresenta pela primeira vez uma sistematização racional da linguagem química tendo como base a associação do nome das substâncias à sua composição e natureza química (nomenclatura binomial). 18 É nas teses do abade de Condillac que Lavoisier e os seus colaboradores irão encontrar a justificação filosófica para a reforma da nomenclatura química. A sua obra Lógique, publicada em 1780 , apresentava a teoria de que todo o raciocínio é algébrico em carácter e que o aperfeiçamento da linguagem a partir figura 7 Os quatro Estados do Processo Alquímico e os quatro elementos. In J. D. Mylius, Philosophia Reformata, Frankfort, 1662.

do modelo da álgebra resultaria no aperfeiçoamento do raciocínio. Condillac defendia, também, que as ideias estavam interligadas aos signos. Daí a importância da linguagem, não apenas como um veículo, mas como um fonte do pensamento (são as palavras que perpetuam os erros e os preconceitos; a lingua não é apenas a expressão do pensamento, ela é também o instrumento da sua produção).Cada linguagem é considerada como sendo um método analítico e a análise é o método científico privilegiado. Condillac justifica também um corte radical com a tradição ao defender que a história nos afasta da natureza e da verdade e que se deve fazer tábua rasa do passado. Este corte vai de encontro aos propósitos revolucionários de Lavoisier, patentes na reforma da nomenclatura.

A substituição do simbologia alquímica pela racionalização da linguagem foi um dos passos decisivos para a emergência da química como ciência moderna no século XVIII. Entretanto, o legado da alquimia como arte tinha sido incorporado nas operaçōes e conhecimentos práti$\cos$ da nova química.

\section{Notas}

As origens da alquimia estão envoltas em mistério. Os dados mais antigos da sua apa- 
figura 8 A primeira chave de Basilio Valentim. s.d.

rição remontam ao Egipto e à Babilónia. Desenvolveu-se também na China (300 a.c.), na India e na Grécia (100 a.c. a 1000 d.c.). A alquimia árabe vai estabelecer-se no século VIII e desempenhar um papel fundamental na sua transmissào ao ocidente no século XII. Sobre as origens da alquimia ver B. Bensaude-Vincent e I. Stengers, História da Química (Lisboa: Instituto Piaget, 1996), Capitulos I e II; Serge Hutin, L'Alchimie (Paris: Presses Universitaires de France, 1951), Capítulo I; Victor Zalbidea (ed.), Alquimia e Ocultismo (Lisboa: Edições 70, 1980), pp. 9 10.

${ }^{2}$ Durante um longo periodo de tempo, o laboratório químico foi uma instituição estável mas não estática. 0 fogo e os fornos foram visual e operacionalmente predominantes até ao século XVIII (não devemos esquecer que no séculos XVII e XVIII a definiçâo mais comum de Química considerava-a uma arte de separar as substâncias que entram na composição dos corpos e de reobter estes corpos a partir das mesmas substâncias, sendo o fogo considerado o agente mais poderoso das transformações químicas). Nos laboratórios alquímicos também já se efectuavam as operaçōes de destilação, sublimação, calcinação e cristalização. A principal novidade nos laboratórios químicos dos finais do século XVIII está na utilização cres cente de alguns instrumentos de precisầo (balanças, termómetros, barómetros) e na utilização de bombas pneumáticas e outros instrumentos para recolha de gases (os gases passam a ter um estatuto químico que até aqui nẫo tinham). Em relação a outros aspectos, os laboratórios praticamente nâo se diferenciavam dos de épocas anteriores. No entanto, o aspecto do laboratório modificar-se-ia gradualmente devido aos seguintes

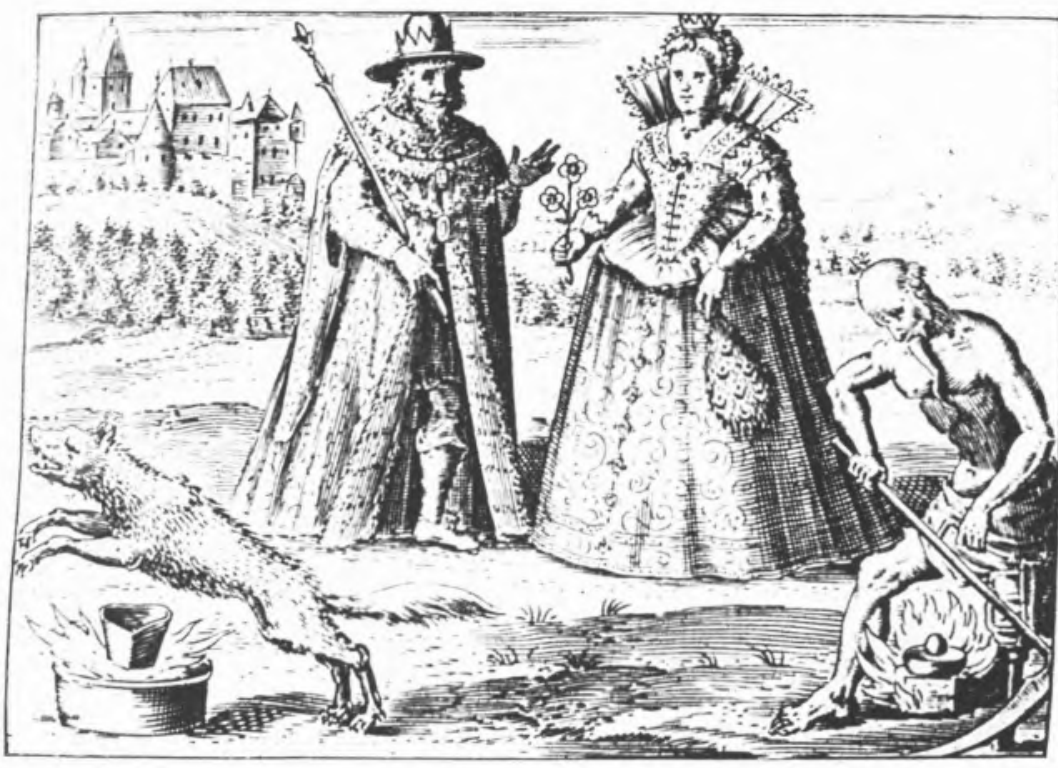

acontecimentos: refinamento das operações, melhoramento de alguns instrumentos, introdução de novos reagentes e indicadores químicos, mudança nos objectivos das operaçôes e nas concepções sobre a natureza das substâncias químicas. No século XIX e particularmente no século XX, os desenvolvimentos da ciência experimental tiveram como consequência o crescimento espectacular do número de instrumentos utilizados num laboratório químico. Assistiu-se a um aumento da sua normalização e grau de precisão. Passou a gastar-se cada vez mais dinheiro com o equipamento de um laboratório, o que teve como consequência a redução quase total do número de laboratórios privados. A prática experimental passou necessariamente a estar ligada a Instituições e a ser um empreendimento colectivo. 0 laboratório passou também a ser o local indispensável para o ensino e treino do cientista.

${ }^{3}$ Para o endimento da alquimia como uma visâo mística do mundo, ver Costa, A. M. Amorim da, Alquimia, Um Discurso Religioso (Lisboa: Vega, 1999).

\section{${ }^{4}$ Podemos considerar a existência de três} tipos de alquimistas. Os primeiros seriam aqueles que apenas tinham como objectivo o enriquecimento pessoal e que muitas vezes enganavam os cidadãos com falsas receitas da Pedra Filosofal. Este tipo de alquimista (ou se quisermos pseudo-alquimista) foì motivo de sátira em alguma literatura da época, como na peça-poema de Ben Jonson, The Alchemist (1612). O segundo tipo de aquimistas englobava aqueles que procuravam um aperfeiçamento pessoal através da meditaçăo, da leitura e, por vezes, do trabalho laboratorial. Criticava-se, sobretudo, o carácter de secretismo da sua actividade e o hermetismo da sua linguagem. O terceiro tipo são os denominados "assopradores", cuja actividade se restringe praticamente ao laboratório (a sua cultura literária é diminuta) e está mais próxima dos artesãos ou daqueles que manejam o ferro na forja. Muitos deles acreditavam na existência da Pedra Filosofal e procuravam-na durante toda a vida, acabando por morrer na miséria. Ver J.

Read, J., Through Alchemy to Chemistry (New York: Harper \& Row Publishers, 1963).

5 -Vejam ... o nosso Salvador ... que eternamente unificará no seu corpo todas as almas puras e limpas e afastará toda as impurezas por não serem merecedoras do seu Corpo divino. Assim e em comparação (mas primeiro pedindo licença às Igrejas Católicas, Apostólicas e Romanas, para falar desta ma neira...) eis aqui o nosso Exlixir branco que de ora em diante unificará inseparavelmente nele toda a natureza Metálica pura, transformando-a na prata mais fina, rejeitando tudo o que seja impuro, estranho, Heterogéneo, ou de outra espécie.", citado em M. Crosland, Historical Studies in the Language of Chemistry, pp. 3-24. (New York: Dover Publications, 1962), p. 11.

${ }^{6}$ Exemplos de alguns titulos de antigos tratados de alquimia onde está patente esta linguagem alegórica sâo: De Occulta Philosophia de H. C. Agrippa (1531); Basilica Chymica de O. Crollius (1609); De interitu alchemiae de G. D. Guiebertus (1614); De secretis naturae de R. Lull (1567) (Bolton, 1882).

${ }^{7}$ Ver G. Debus, Man and Nature in the Renaissance (Cambridge: Cambridge University Press, 1978), Capitulo. 2.; C. Merchant, C., The Death of Nature: Women, Ecology and the Scientific Revolution (San Francisco:Harper Collins, 1983), Capitulo IV; J. Henry, "Magic an Science in the Sixteenth and Se- 
venteenth Centuries.", in Companion to the History of Modern Science, R. C. Colby, G.

N. Cantor, J. R. R. Christie e M. J. S. Hodge (eds.) (London and New York: Routledge, 1990), pp. 583-596.

${ }^{8}$ G. Debus, G., Man and Nature in the Renaissance (Cambridge: Cambridge University Press, 1978), Capítulo II; e Costa, A. M. Amorim da, Alquimia, Um Discurso Religioso (Lisboa: Vega, 1999), pp. 65-81.

${ }^{9}$ Citado em M. Crosland, Historical Studies in the Language of Chemitry, (New York: Dover Publications, 1962), p. 6

${ }^{10}$ Victor Zalbidea (ed.), Alquimia e Ocultismo (Lisboa: Ediçōes 70, 1980),pp. 123-124

${ }^{11}$ Basílio Valentim, segundo rezam os seus escritos, foi um monge pertencente à Ordem Beneditina de S. Pedro de Erfurt e viveu nos princípios do século XV. No entanto, segundo alguns estudiosos, os manuscritos não podem ser anteriores ao século XVII. Victor Zalbidea (ed.), Alquimia e Ocultismo (Lisboa: Edições 70, 1980), p 117.

${ }^{12}$ A máxima lege, lege, relege, ora, labora popular entre os alquimistas traduzia a importância renovada da leitura e as dificulda- des inerentes à interpretação dos textos alquímicos.

${ }^{13}$ Segundo Owen Hannaway, as origens da Química como uma disciplina distinta e passivel de instrução, remontariam precisamente ao livro Alchemia de Andreas Libavius e que viria a ser um modelo para muitos dos tratados de Química posteriores. Este livro representaria a primeira síntese que pretendia integrar as técnicas e preparações da Química, apresentando-a como uma matéria digna de estudo devido ao seu valor intrínseco: "Alchemia is the first text which conceives of chemistry as an independent and integral discipline divorced from its pplications and which seeks to organize the techniques and prescriptions of the subject in such a way that can be taught. As such, it is more than a late sixteeth-century encyclopedia of operations and recipes of the various chemical arts. It marks the appearence of a new scholarly discipline on the intellectual horizon - the discipline of chemistry." O. Hannaway, The Chemists and the Word: the didactic origins of chemistry (Baltimore: Johns Hopkins University Press, 1975), p. 143).
${ }^{14}$ M. Toxites, Onomasticon (Argentorati, 1574), p. 11-13.

${ }^{15}$ R. Boyle, The Sceptical Chymist or Chymico-physical Doubts and Paradoxes (Oxford, 1680), pp. 200-1.

${ }^{16}$ Os estudos de J. B. van Helmont, J.

Mayow e S. Hales já tinham sugerido a existência de diferentes tipos de gases, mas não foram convincentes para os químicos da época. Ver A. J. Ihde, The Development of Modern Chemistry (New York: Dover Publications, 1984), Capítulo II.

${ }^{17}$ T. Frangsmyr, "Linnaeus and the Classification Tradition in Sweden", in The Structure of Knowledge: Classifications of Science and Learning Since the Renaissance (Berkeley: University of California, 2001), pp. 77-92.

Sobre a reforma da nomenclatura química em 1787 ver A. M. Nunes dos Santos, "Nota de Apresentação" e "Prefácio" à edição facsimilda do Méthode de Nomenclature Chimique (Lisboa: Edição da Petrogal, s.a., 1991) e B. Bensaude-Vincent e I. Stengers, História da Química (Lisboa: Instituto Piaget, 1996), Capítulo XIV.

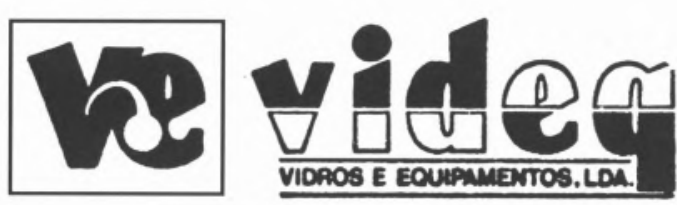

Equipamento de Laboratório

Balanças - Centrifugas - Aparelhos de $\mathrm{pH}$ - Tituladores

Condutímetros - Agitadores - Espectrofotómetros

Microscópios - etc.

Vidros e Plásticos de Laboratório

Distribuidores NORMAX

Material Didáctico

Ensino Secundário e Superior

Representantes exclusivos SISTEDUC - Sistemas Educativos S.A.

Rua Soeiro Pereira Gomes, 15 r/c Frente

Bom Sucesso - 2615 Alverca

Telefs. (01) 95704 20/1/2 - Fax (351-1-957 04 23) - Portugal 


\section{Olimpíadas de

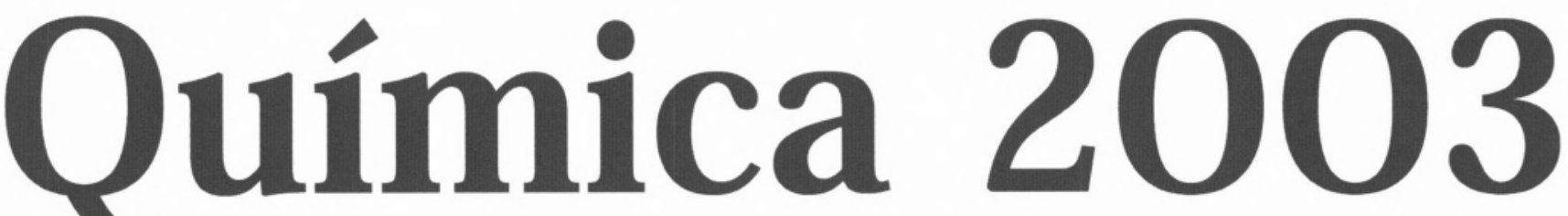

As "Olimpíadas de Química" estão de novo em marcha!

Este ano não há razão para não participar!!

E há muitas razões para não perder!!! *

* Lista de razōes demasiado extensa para este espaço. Por favor ver

$$
\text { www.spq.pt }
$$

Paulo Ribeiro Claro

Departamento de Química

Universidade de Aveiro

P-3810-193 AVEIRO

e-mail: pclaro@dq.ua.pt

Olimpíadas de Química 2003

Ficha de inscriąão

(até 31 de Janeiro de 2003)

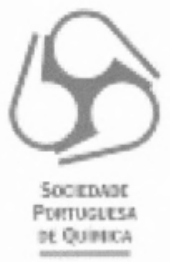

ESCOLA

Morada

CONTACTOS

Tel.:

FAX:

E-mail:

EQUIPA

\begin{tabular}{|ll|}
\hline Professor acomnanhante: & \\
\hline Alunn: & Data Nasc: \\
\hline Alunn: & Data Nasc: \\
\hline Alunn: & Data Nasc: \\
\hline
\end{tabular}

